\title{
NUMERICAL DETERMINATION OF THE EFFECTS OF OUT-OF- PLANE WAVINESS IN THERMOPLASTIC MATRIX LAMINATES
}

\author{
C. Fougerouse $^{1,2 *}$, C. Fagiano' ${ }^{2}$, M. Hirsekorn ${ }^{2}$, F. Laurin ${ }^{2}$, M. Desailloud ${ }^{1}$, M. Herman ${ }^{1}$ \\ ${ }^{1}$ AIRBUS Operations, Airframe Engineering, Toulouse, France \\ ${ }^{2}$ ONERA, DMAS, Université Paris-Saclay F-92320 Châtillon, France \\ *claire.fougerouse-ext@onera.fr
}

Composite laminates with thermoplastic matrices are potential candidates for structural applications in aerospace. As a new material, investigations are needed to support parts quality definition. Indeed, manufacturing defects, such as out-of-plane waviness, may be accepted in composite structures if they do not significantly affect the performances of the part. Waviness defects are known for having an impact on the longitudinal compressive strength $[1,2]$; but they were mainly studied in thermoset matrix components.

The objective of this study is to numerically assess the effects of out-of-plane waviness within laminates with unidirectional plies (made of carbon fibres and a thermoplastic matrix), on the elastic properties and, damage onset and kinetics. An experimental campaign was performed at ONERA to calibrate and validate the numerical results.

First, an analytical description of defect geometries is proposed based on experimental observations of specimens of industrial interest. The extracted parameters have a physical meaning, e.g. the defect extent or the amplitude. The parametrised description is validated by comparison with waviness shapes observed on microcuts (Figure 1.a) and, soon, on Computerized Tomography scan images. The mechanical representativeness is also studied comparing the knock-down factors - ratio between defect and pristine configurations - obtained by simulations on the real geometry and on the parametrised mesh (Figure 1.b).

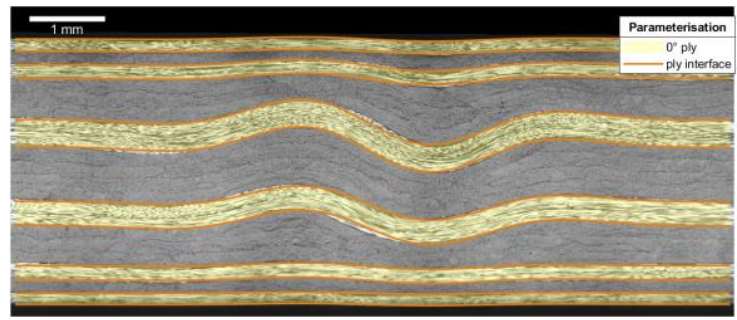

(a)

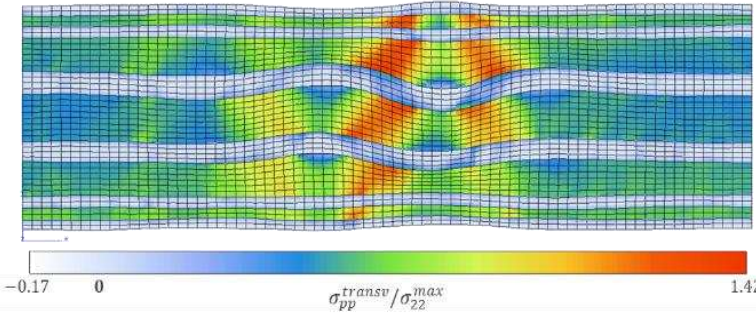

(b)

Figure 1. a) Superposition of a defect micrograph with its corresponding parametrised description. b) Maximum principal transverse stress field obtained with the parametrised mesh under tensile load.

Then, by means of a sensitivity study, the parameters having the strongest influence on the mechanical response, including the damage scenario, are determined. For example, among the seven primary parameters investigated in scope of the study, the amplitude and the wavelength are the most influent on the local knock-down of elastic properties of a cross-ply laminate under tensile loading. The parametrisation is finally used to generate multiple defect configurations from which a metamodel, linking defect geometries with knock-down factors on mechanical properties, will be identified.

\section{References}

[1] S. Mukhopadhyay, M. Jones and S. Hallett (2015) Compressive failure of laminates containing an embedded wrinkle; experimental and numerical study. Composites Part A, 73, 132-142.

[2] N. Xie, R. Smith, S. Mukhopadhyay and S. Hallett (2018) A numerical study on the influence of composite wrinkle defect geometry on compressive strength. Materials and Design, 140, 7-20. 